\title{
Morbidity and mortality patterns of neonates admitted to neonatal intensive care unit in tertiary care hospital, Bhopal
}

\author{
Kumar $\mathbf{S}^{1}$, Ahmed $\mathbf{M}^{2}$, Anand $\mathrm{S}^{3}$ \\ ${ }^{1}$ Dr. Saurabh Kumar, Assistant Professor, ${ }^{2}$ Dr. Minhajuddin Ahmed, Assistant Professor, ${ }^{3}$ Dr. Shweta Anand Professor; \\ all authors are attached with Department of Paediatrics, CMCH, Bhopal.
}

Address for Correspondence: Dr. Saurabh Kumar, Email- varshneysaurabh2@gmail.com

\begin{abstract}
Introduction: Neonatal period is the most vulnerable period of life when morbidity and mortality is considered. Neonatal outcome is an important indicator in obstetric and neonatal health care. In developing countries, death during the newborn period accounts for $50-70 \%$ of infant mortality. In India 1 million babies die every year. This study was conducted to know the various causative factors leading to morbidity and mortality in neonate at a tertiary care hospital. Study Design: Retrospective study. Material and method: This retrospective study was done on 279 neonates who were admitted at Chirayu Medical College and Hospital, Bhopal in neonatal intensive care unit (NICU) in the Department of Paediatrics from May 2014 to May 2015. Results: A total of 279 neonates were admitted in NICU during the study period. A total of $244(87 \%)$ were inborn and $35(13 \%)$ were out-born neonates. The major cause of morbidity was neonatal sepsis (25\%), prematurity (19\%), neonatal jaundice (18\%), birth asphyxia (5\%) and cardiac anomaly $=4 \%$. The overall mortality rate was $11 \%$. Most deaths were due to sepsis (28\%), prematurity with RDS (18\%) and birth asphyxia (9\%). Conclusion: Good antenatal care, proper nutrition to pregnant women, timely referral, prevention of preterm delivery are important steps to decrease neonatal morbidity and mortality.
\end{abstract}

Key words: Neonates, Mortality \& morbidity patterns, Neonatal intensive care unit

\section{Introduction}

Every year globally, four million neonates die in the first 4 weeks of life [1]. Neonatal period is the most vulnerable period of life due to different diseases, especially in preterm and low birth weight babies. These diseases are preventable in majority of cases [2]. In a report published in Lancet, major direct cause of neonatal mortality were preterm birth $(27 \%)$, infection (26\%), asphyxia (23\%), Congenital anomaly (7\%), others $(7 \%)$, tetanus $(7 \%)$ and diarrhea $(3 \%)$ [3].

In India, out of 25 million babies born, around one million of babies die every year. India contributes to $25 \%$ of neonatal mortality around the world. According to national family health survey the current neonatal mortality rate is $39 / 1000$ live birth, accounting for nearly $77 \%$ of all the infant death $(57 / 1000)$ and nearly half of the under five child deaths (74/1000) [4]. Within the first month, one quarter to one-half of all the death occur within first $24 \mathrm{hr}$ of life and $75 \%$ occur in

Manuscript received: $25^{\text {th }}$ September 2016

Reviewed: $10^{\text {th }}$ October 2016

Author Corrected; $20^{\text {th }}$ October 2016

Accepted for Publication: $2^{\text {nd }}$ November 2016 the first week. First 48 hrs immediately following birth is the most crucial period for newborn survival [5]. The primary outcome of this study was to know the spectrum of diseases leading to Morbidity and Mortality Patterns of Neonates and the commonest cause of the same. The secondary outcome was to list the measures to prevent the various causes of morbidity and mortality of a neonate.

\section{Methodology}

Material and method- This retrospective study was done on 279 neonates who were admitted at Chirayu Medical College and Hospital, Bhopal in neonatal intensive care unit (NICU) in the Department of Paediatrics from May 2014 to May 2015.

A pre-designed proforma was made. According to already designed proforma data of all admitted babies were listed out and categorized on basis of age during admission, sex, type of delivery, length of stay, birth weight, gestational age, inborn or out-born delivery, 
indication for admission, bacteriological profile and procedure done during hospitalization.

Sepsis and meningitis were diagnosed on clinical grounds along with $\mathrm{C}$-reactive protein (CRP), complete blood count (CBC), positive blood culture and cerebrospinal fluid (CSF) examination. Congenital heart disease was diagnosed with Chest X-Ray and then confirmed by echocardiography. Birth Asphyxia was diagnosed clinically and hypoxic ischemic encephalopathy (HIE) by Sarnat and Sarnat Staging [6].

Diagnosis of prematurity was clinical or it was based on the WHO definition for prematurity (live born neonates delivered before 37 weeks from 1st day of last menstrual period) and using new Ballard scoring [7]. Low birth weight was defined as when birth weight was less than $2500 \mathrm{~g}$.

\section{Result}

A total of 279 neonates were admitted in NICU during study period. Of the total admission, 244 (87\%) were inborn and 35 (13\%) were out-born neonates. Among 279 newborn, 145 (52\%) were male and 134 (48\%) were female. (79\%) babies were term, $(17 \%)$ were preterm and $(2 \%)$ were extremely preterm. Low birth weight babies were $(35 \%)$ and intra uterine growth restricted babies were $(10 \%)$.

The major cause of morbidity observed was neonatal sepsis (25\%), prematurity (19\%), followed by birth asphyxia and cardiac anomaly. In sepsis, the most common organism grown on blood culture was Klebsiella (37\%), E coli (21\%) followed by Pseudomonas (13\%), Acinitobacter (11.5\%) and Enterobacter (8\%). 5\% babies were admitted with birth asphyxia. Among all birth asphyxia, HIE stage 1 was present in $60 \%$, HIE stage 2 in (26\%) and HIE stage 3 in (14\%). Hypoglycemia, cardiac anomaly, congenital malformations, and NEC each contributed 4\% to morbidity. The common procedures performed during study were umbilical line insertion, lumbar puncture, surfactant administration and double volume exchange transfusion. The overall mortality rate were (11\%) and left against medical advice (LAMA) were (8\%). Twenty-five neonate required mechanical ventilation, out of which $68 \%$ improved $30 \%$ expired and $13 \%$ left against medical advice. The major cause of mortality in declining order was sepsis (28\%), birth asphyxia (20\%) followed by prematurity with RDS (18\%) and cardiac anomaly (15\%).

Table-1: Mode of admission.

\begin{tabular}{|c|c|c|}
\hline Admission & Number & Percentage \\
\hline Inborn & 245 & $87 \%$ \\
\hline Outborn & 35 & $13 \%$ \\
\hline
\end{tabular}

Table-2: Genderwise distribution.

\begin{tabular}{|c|c|c|}
\hline Admission & Inborn & Out-born \\
\hline Male & 122 & 25 \\
\hline Female & 122 & 10 \\
\hline Total & $\mathbf{2 4 4}$ & $\mathbf{3 5}$ \\
\hline
\end{tabular}

Table-3: Distribution of organisms isolated from blood.

\begin{tabular}{|c|c|}
\hline Organism & Number \\
\hline Klebsiella & $14(37 \%)$ \\
\hline E Coli & $8(21 \%)$ \\
\hline Pseudomonas & $5(13 \%)$ \\
\hline Enterobacter & $4(11.5 \%)$ \\
\hline Acinitobacter & $3(8 \%)$ \\
\hline Burkuldhoria & $2(5 \%)$ \\
\hline Enterococcus & $1(2 \%)$ \\
\hline Total & $\mathbf{3 7}(\mathbf{1 3 \%})$ \\
\hline
\end{tabular}


Table-4: Procedure performed.

\begin{tabular}{|c|c|c|}
\hline Procedure & Number & Percentage \\
\hline Umbilical venous line & 10 & $3.5 \%$ \\
\hline Lumbar puncture & 8 & $2.5 \%$ \\
\hline Surfactant administration & 6 & $2.4 \%$ \\
\hline Chest drain & 2 & $0.7 \%$ \\
\hline Double volume exchange transfusion & \\
\hline
\end{tabular}

Table-5: Morbidity profile.

\begin{tabular}{|c|c|c|}
\hline Morbidity Profile & Admission & Percentage \\
\hline Sepsis with meningitis & 71 & $25 \%$ \\
\hline Neonatal jaundice & 52 & $18 \%$ \\
\hline Prematurity & 54 & $10 \%$ \\
\hline Intrauterine growth restriction & 30 & $4 \%$ \\
\hline Necrotizing enterocolitis & 12 & $4 \%$ \\
\hline Cardiac anomaly & 12 & $4 \%$ \\
\hline Congenital anomaly & 12 & $5 \%$ \\
\hline Birth asphyxia & 15 & $3.5 \%$ \\
\hline Meconium aspiration syndrome & 10 & $3.5 \%$ \\
\hline Hypoglycemia & 10 & $0.7 \%$ \\
\hline
\end{tabular}

Table-6: Outcome of neonates.

\begin{tabular}{|c|c|c|c|c|}
\hline Disease & Number & Improved & expired & LAMA \\
\hline Sepsis & 71 & $55(78 \%)$ & $9(12 \%)$ & $7(10 \%)$ \\
\hline Prematurity with RDS & 54 & $42(77 \%)$ & $6(11 \%)$ & $6(12 \%)$ \\
\hline Neonatal jaundice & 52 & $50(96 \%)$ & 0 & $2(4 \%)$ \\
\hline Perinatal asphyxia & 15 & $11(73 \%)$ & $3(20 \%)$ & $1(7 \%)$ \\
\hline Cardiac anomaly & 12 & $5(42 \%)$ & $5(42 \%)$ & $2(16 \%)$ \\
\hline Congenital anomaly & 7 & $3(42 \%)$ & $3(42 \%)$ & $1(16 \%)$ \\
\hline Meconium aspiration syndrome & 7 & $5(72 \%)$ & $1(30 \%)$ & $1(13 \%)$ \\
\hline
\end{tabular}

\section{Discussion}

There were total of 244 delivery (inborn), out of which $158(64 \%)$ were born by caesarean sections (LSCS) and $36 \%$ by vaginal (NVD) and instrumental deliveries. There was a slight male predominance (M:F ratio$1.1: 1)$ in our study which was also documented by Mani kant et al [8].

$35 \%$ babies were low birthweight and $20 \%$ babies were preterm. This may be due to the poor maternal health status, poor antenatal check up and the poor socioeconomic status of the families. According to the
UNICEF "The State of the World's Children 2010" report, $28 \%$ neonates are born with low birth weight in India [9].

The most common morbidity for admission was sepsis (25\%) followed by prematurity (19\%) and perinatal asphyxia [10]. According to national neonatal- perinatal database (NNPD) sepsis (36\%) is the most common morbidity responsible for admission followed by prematurity (26.5\%) and perinatal asphyxia (10\%) [11]. Neonatal sepsis is an important cause of morbidity and 
mortality especially in VLBW and ELBW. So appropriate management of neonates with sepsis can reduce neonatal morbidity and mortality and help to achieve Millennium Development Goals.

Culture-positivity for aerobic organisms in neonates varies from $25 \%$ to $60 \%$ [10]. In this study, blood culture-positivity rate was $13 \%$. This finding was comparable with other reports [12]. The most common organism was Klebsiella (37\%), followed by E coli (21\%), Pseudomonas (13\%) which is similar to National Neonatal-Perinatal database report in which also Klebsiella is the predominant (29\%) pathogen [13].

In our study sepsis (28\%), prematurity (18\%), cardiac anomaly (15\%), perinatal asphyxia (9\%) were most common cause of mortality. Study published by ICMR documented sepsis $(32.8 \%)$ was the major cause of neonatal mortality [14]. Also it observed that in our study babies who require mechanical ventilation had higher mortality rate as compared to those who don't require ventilation. This indicates that mortality depend upon stage of the disease and facilities available in NICU.

In this study overall mortality rate was $11 \%$ which is similar to study done by Jan et al [15]. Other studies have reported higher mortality rates [16]. The major cause of death in this study was sepsis. This might be due to poor antenatal care, maternal malnutrition, higher rate of preterm baby, low birth weight, infrastructure of NICU and also depends upon the care given by the expertise of trained NICU staff.

\section{Conclusion}

In today's scenario, sepsis is still the most common cause of mortality. Prevention of sepsis is most important step in neonatal death. Hand washing and strict infection control in NICU unit and judicious use of antibiotic can prevent sepsis in NICU.

Preventive measures as highlighted above should focus on recognition of high risk infants with prompt laboratory screening for sepsis and early instituition of empirical antibiotic based on local data. Such approaches would be safe and cost effective strategy especially in developing countries.

Good antenatal care, proper nutrition to pregnant women, timely referral, prevention of preterm delivery are important steps to decrease neonatal morbidity and mortality. In spite of newly established tertiary care hospital and shortage of staff, our hospital has good survival rate of newborn.

Funding: Nil, Conflict of interest: Nil Permission from IRB: Yes

\section{References}

1. Jehan I, Harris H, Salat S, Zeb A, Mobeen N, Pasha O, McClure EM, Moore J, Wright LL, Goldenberg RL. Neonatal mortality, risk factors and causes: a prospective population-based cohort study in urban Pakistan. Bull World Health Organ. 2009 Feb;87 (2):130-8.

2. Rahim F, Jan A, Mohummad J, Iqbal H. Pattern and outcome of admissions to neonatal unit of Khyber Teaching Hospital, Peshawar. Pakistan Journal of Medical Sciences. 2007 Apr 1;23 (2):249.

3. Lawn JE, Cousens S, Zupan J; Lancet Neonatal Survival Steering Team. 4 million neonatal deaths: when? Where? Why? Lancet. 2005 Mar 5-11;365 (9462):891-900.

4. NFHS-3: Ministry of health and family welfare, Govt of India. Available at URL: http://www.mohfw. nic.in/NFHS-PRESENTATION. htm.

5. Children: reducing mortality,WHO media centre [internet].2012 june [cited 2015 aug 16]. Available from : http: //www.who.int / mediacentre / factsheet / fs178/ en /index.html.

6. Sarnat HB, Sarnat MS. Neonatal encephalopathy following fetal distress. A clinical and electro encephalographic study. Arch Neurol. 1976 Oct; 33 (10):696-705.

7. Ballard JL, Khoury JC, Wedig K, Wang L, EilersWalsman BL, Lipp R. New Ballard Score, expanded to include extremely premature infants. J Pediatr. 1991 Sep;119(3):417-23.

8. Kumar MK, Thakur SN, Singh BB. Study of the Morbidity and the Mortality Patterns in the Neonatal Intensive Care Unit at a Tertiary Care teaching Hospital in Rohtas District, Bihar, India. J Clin Diagn Res. 2012; 6(2):282-5.

9. UNICEF. The state of the world's children, 2010. New York: UNICEF 2010: 92-95. 
10. Jain S, Jain P, Verma M, Chacko B, Dani VS, Agarwal DP, Kiratkar RK, Shanmughasundaram R, Padmapriya E, Swaminathan L, Jaishree RA. Morbidity and mortality among outborn neonates at 10 tertiary care institutions in India during the year 2000. Journal of Tropical Pediatrics. 2004 Jun 1;50(3):170-4.

11. Mathur NB.Neonatal sepsis. Indian Pediatr. 1996 Aug;33(8):663-74.

12. Shrestha P, Das BK, Bhatta NK, Jha DK, Das B, Setia A, Tiwari A. Clinical and bacteriological profiles of blood culture positive sepsis in newborns. Journal of Nepal Paediatric Society. 2007;27(2):64-7.
13. Paul VK. Neonatal morbidity and mortality: report of the national neonatal and perinatal database. Indian Pediatr. 1999 Feb;36(2):167-9.

14. ICMR Young Infant Study Group. Age profile of neonatal deaths. Indian Pediatr. 2008 Dec;45(12):991-4.

15. Jan AZ, Ahmad S, Zahid SB. Clinical audit of admission pattern and its outcome in a neonatal ICU. Gomal Journal of Medical Sciences. 2013 Jun $30 ; 11(1)$.

16. Parkash J, Das N. Pattern of admissions to neonatal unit. J Coll Physicians Surg Pak. 2005 Jun;15(6):341-4.

\section{How to cite this article?}

Kumar S, Ahmed M, Anand S. Morbidity and mortality patterns of neonates admitted to neonatal intensive care unit in tertiary care hospital, Bhopal. Int. J Pediatr Res. 2016; 3(11):776-780.doi:10.17511/ijpr.2016.i11.01. 